\title{
AN ANALYSIS OF THE IMPACT OF UTAUT PREDICTORS ON THE INTENTION AND USAGE OF ELECTRONIC HEALTH RECORDS AND TELEMEDICINE FROM THE PERSPECTIVE OF CLINICAL STAFFS
}

\author{
P. Venugopal' ${ }^{1}$ S. Aswini Priya ${ }^{2}$, V. K. Manupati ${ }^{3}$, M. L. R. Varela ${ }^{4}$, J. Machado5, G.D. Putnik ${ }^{6}$ \\ 1,2,3 School of Mechanical Engineering, Department of Manufacturing, VIT, Vellore, Tamil Nadu, India \\ 4,5,6 Department of Production and Systems, School of Engineering, University of Minho, Guimarães, Portugal \\ pulidindivenu@gmail.com, aswinipriya.s@vit.ac.in, manupativijay@gmail.com,leonilde@dps.uminho.pt \\ jmachado@dem.uminho.pt, putnikgd@dps.uminho.pt
}

\begin{abstract}
Technology adoption play significant role for good healthcare services. It is very important to understand and identify the requirements and perceptions of hospital employees for the implementation of technology in their work place. This study determines the impact of performance expectancy, effort expectancy and social influence on behavioural intention as well as the impact of facilitating conditions on technical/clinical staff's perspective. The structured questionnaire is administered to 770 clinical staffs on the usage of telemedicine and electronic health records in hospitals. A valid sample of 568 was returned back for further analysis. Regression analysis using AMOS 20 is performed to examine the effect of the constructs. Findings revealed that performance expectancy, effort expectancy, and social influence have a significant impact on behavioural intention and facilitating condition also significantly impacts behavioural intention which in turn impacts usage behaviour of electronic health records and telemedicine. The limitations and future research are suggested and delineated.
\end{abstract}

Keywords: Electronic health records, Telemedicine, performance expectancy, Effort expectancy, social influence, Facilitating conditions, Behavioural intention.

\section{Introduction}

Medicine among Primitive Peoples was evident of surgery in skulls from the Stone Age. Primitive people used different experiments for their injuries, for example Australian Aborigines covered broken arms in clay, which hardened in the hot sun. Cuts were covered with fat or clay and bound up with animal skins or bark. Whereas Ancient Egyptian Medicine was about $3000 \mathrm{BC}$ the curtain rises on Egyptian civilization. Egyptian doctors used a huge range of drugs obtained from herbs and minerals. They were drunk with wine or beer or sometimes mixed with dough to form a 'pill'. Secondly, Ancient Greek Medicine had its roots in modern medicine are in ancient Greece. People who were ill-used to offer sacrifices to the god and sleep overnight in the temple. Greek doctors developed a rational theory of disease and sought cures. However one did not replace the other. Finally, the Roman Medicine conquered Greece and afterward, doctors in the Roman Empire were often Greeks.

In India after agriculture healthcare is the largest sector offering more employment and generating more revenue. The Indian healthcare is divided into two categories one is public/government and second one is private.

Government sector healthcare Institutions are very limited in number in few cities, primary healthcare centres in rural areas whereas most of the private sector healthcare institutions are in urban areas.

There are well trained medical/healthcare professions and the cost wise it is very low when compared to US and Western countries. The present Indian healthcare market size is US $\$ 100$ billion and anticipated to grow up to US $\$ 280$ billion by 2020 with 22.9 compound annual growth rate.

According to department of industrial policy and promotion, Indian hospitals and diagnostic centres are drawing the Foreign Direct Investment too. To promote health industry in India, Social Endeavour for Health and Telemedicine was introduced to rural population through information technology accessibility, improving the skills and by introducing the technologies for the success of 'Digital India'. Another initiative by Government of India is the agreement between Sweden and India for improving the quality of health through the technology innovation and research and development. 
Prime Minister of India, initiated E-health services with an objective to offer effective and economical healthcare services to all people through electronic health records, for instance to get online appointments.

\section{Statement of the Problem}

As on March 2011, Indian population was Rs. 121 crore, out of which Rs. 83.3 crore $(68.84 \%)$ live in rural areas while 37.7 crore (31.6\%) live in urban areas, as per census of India. The access of healthcare services is not yet achieved fully in many developing countries, even though it is guaranteed for all people throughout the world. Particularly in rural area of developing countries are unable to access health care services. As per World Health Organization, a pregnant women should have at least four times Anatanal care (ANC) by a trained health provider. According to the Deloitte report of 2015, the estimation of expenditures allotted to this sector is five percent of Gross Domestic Product (GDP) in 2013 and it is anticipated to remain stable till 2016. In terms of infrastructure, India has only one bed for every 1050 patients and yet it accounts for 100000 beds at present decade with an investment of about $\$ 50$ billion. And it also lacks in qualified medical professionals to efficiently diagnose the diseases through the proper delivery of services. The report states that doctor-patient ratio is considerably lower in India than World Health Organization statistical report the ratio of India is about 0.7 doctors and 1.5 nurses per 1000 people which is comparatively lower than 2.5 doctors and nurses per 1000 people. As there is a scarcity of doctors and nurses in India, opting for traditional method of services is seem to be not effective and difficult for patients to access to it. The problem also includes traditional consultation process which is very lengthy and time consuming in urgency cases, long-distance travel times, improper and inefficient delivery of services and nontechnology up gradation in the past.

All these factors contributed to the significant adoption of telemedicine in India. Kai Zheng et al. (2005) studied about the behaviour of receipt and espousal of the clinical system from the perspective of clinicians for continual sickness and precautionary care management.

The technology tested is useful for taking the appointment of the doctor; information of the patient can be browsed, reminding the doctors' directions, for recording the significant symptoms. It was found that there was a larger confrontation. Zaidi in 2008 [11] measured the clinicians' perceptions and usefulness of a web-based antibiotic approval system and the future need to be carried on the adoption of other technologies.

\section{Literature Review}

Dixon and Dixon (1994) (4) studied the adoption of technology-enabled innovations by primary care physicians. The method used to do it is by developing several questions from several sources. They were modified to the level of clinical psychologists. The result of this is it acts as a useful tool to gain knowledge about implementing IT innovations. Future research is to do survey with refined questions and send it to community physicians to allow a rational development of continuing medical education programs and computer resources to facilitate the implementation in physicians' office.

Zaidi [11] studied about measuring clinicians' perceptions and usefulness of a web-based antibiotic approval system. Methods used were surveying the junior medical staff, senior medical staff, and pharmacists. This consists of five-point scale to measure clinicians' usage of computers etc. Results found to be a number of clinicians perceptions about the system correlated with the actual usage of the system by clinicians. Future research has to be done using similar measures on other decision support systems will improve the understanding of the clinicians.

Chiang et al. [3] studied about assessing the current state of health record use by ophthalmologists including adoption rate and user satisfaction. Methods used were surveying the randomly selecting people based on geography to participate in a study of EHR adoption. Results from this are adoption rate of ophthalmology practices is low. The satisfaction of those who were already using is high. Future research has to be done on user satisfaction with electronic health recording systems.

Jelena Zurovac et al. and others [10, 12] studied the adoption of electronic health records in primary care practices. The survey was conducted on adult patients alone. Results are Data security AND confidentially are important for a patient because all are not ready to share their problem with others. A survey was conducted online .670 patients reported a favourable percentage was 57 . Most patients found that EMR improved quality of care and confidentiality of their reports. Some patients felt that there is a relationship gap between patients and doctors. This may spoil the patient-provider relationship. Future research has to be done in a large manner and should find out the technology adoption. Katzenstein et al. [7] elaborate their view on how telemedicine is an innovative technique in healthcare delivery. This article proposes the strategic design of a project to radically redesign the delivery of health care in Cameroon. 
The strategy delivers many major elements of parental care, postnatal care, vaccinations, HIV/AIDS testing and many more. The project in the article also improves the education system related to healthcare. The project was designed with respect to the national view. In future Ministry of Health and Health Span International will collaborate to create a program to expand the employment of available healthcare staff to include recruitment, in-service training, and development of underutilized nurses in Cameroon.

Timothy Bickmore et al., in 2013 [2] examined the clinical staff perception on the adoption of technology for healthcare services. Professionals seem to be afraid of technology due to an assumption that technology will replace them, so resisted the technology. When it comes to nurses' majority of them significantly showed interest in technology adoption. To earlier researchers on technology adoption to healthcare found that the intention and actual use of technology are voluntary. The US government spent huge money on implementation and execution of technology in healthcare but there are many barriers to its adoption to clinicians. In the present study patient education system introduced in medical services been tested by using technology adoption model; which revealed that the actual use can be estimated with the intention to use and perceived ease of use. The technology tested can avoid re-hospitalization and facilitates self-care of the patient after discharge from the hospital. From the earlier studies, authors identified that the acceptance of technology among doctors, nurses and clinical staff was done but the complex model unified theory of acceptance and use of technology was not tested.

Gheorghe and Petre [4] from Bucharest University of Economic Studies say that medical system is facing a wide range of challenges nowadays due to changes that are taking place in the global healthcare systems. The one-time solution for this is Integrating Data Mining Techniques into Telemedicine Systems. New partnerships are made between medical care systems and the IT industry. He proposes that data mining is a domain of great importance and can provide valuable information for patient's diagnosis and treatment planning. This article mainly discusses the data mining techniques and systems for healthcare organizations. The article clearly explains how data mining has clearly integrated into the medical field. The data Domain is a dynamic fast expanding domain that improves the quality of the medical field for humans. The business process management try's to improve the process in an organization, they clearly state that data mining techniques into telemedicine refine the processes involved in the system.

Jeyakodi and Herath, and others [5, 6] explored the factors that influence Electronic Medical Records adoption in Sri Lanka teaching hospitals. The study employed UTAUT model from physicians' perspective. The findings showed that performance expectancy, effort expectancy significantly influences behavioural intention which in turn influences actual use behaviour of EMR in hospitals. Surprisingly there is no impact of social influence on behaviour intention and also there is no impact of facilitating conditions on actual use behaviour which actually contradicts with the findings of previous studies.

Narattharaksa et al. [8] examined the aspects that influence the adoption of Electronic Medical Record from the perspective of Thailand healthcare industry. The results showed that two factors highly impact the adoption of EMR in the healthcare industry. The factors include managerial expertise and technical expertise. The managerial expertise consists of six sub factors such as clinical staff involvement, adequate budget allocation, effective EMR project communications, EMR functions support administrative processes, clear EMR project goals and scope, EMR functions support medical decisions whereas technical expertise consists of six sub factors such as training in the EMR systems, training to improve technical skills, EMR vendors, knowledge and expertise of IT staff, good electric communications and connectivity, EMR suits department user needs.

AlDossary et al., in 2017 [1] reviewed the methodology employed in assessing telemedicine service inventiveness in hospital amenities. The findings revealed that majority of the services were constructed in USA and $2 / 3 \mathrm{rd}$ of the services were provided by real-time telemedicine. The telemedicine services were assessed from three different aspects such as satisfaction, clinical outcomes, and economics. This result is reported by half of the studies whereas the remaining half reported their activities and services without any assessment measures.

Tavares and Oliveira [9] portrayed the factors that drive the adoption of Electronic Health Records portal in the United States and Europe. The study employed UTAUT2 and CFIP framework to determine the purpose. The results revealed that performance expectancy, effort expectancy, social influence, price value, hedonic motivation, and habit significantly impacts behavioural intention, which in turn, also habit influences usage behaviour of adoption EHR portal. As this study is carried out cross-culturally, in the United States only three predictors are found to be highly significant such as hedonic motivation, social influence, and price value. The intention to adopt EHR portal accounted for $53 \%$ of variance whereas use behaviour of EHR portal accounted for $36 \%$ of the variance.

- What is the effect of the performance expectancy, effort expectancy and social influence on behavioural intentions? 
- What is the effect of facilitating conditions and behavioural intention on usage behaviour of technical/clinical staff on acceptance of the use of electronic health records and telemedicine?

\section{Methodology}

The hospital employees' especially technical/clinical staff is the sampling units for the study. In particular technical/clinical staff from Vellore District in Tamilnadu has been selected as the sampling unit for the study. Healthcare sector has been chosen for the study purpose of the research. Convenience sampling was adopted to select the clinical staffs from the identified hospitals of Vellore. Convenience sampling would guarantee the availability of the respondents could be included in the sample. A sample of 770 clinical staff was contacted for elucidating their responses, out of which 568 clinical staff willingly filled up the questionnaire after filling the missing values with mean series all the respondents have been chosen for the final study. In the present research, compiles of both primary as well as secondary data sources. The secondary data sources include a database of referred journals from Emerald publishers, EBSCO, IEEE, MIS quarterly etc. other secondary data sources like government reports, conference proceedings and other sources.

The primary data associated to the demographic and the perceptions of respondents on performance expectancy, effort expectancy, social influence, facilitating conditions, behavioural intention and usage behaviour of electronic health records and telemedicine were collected by administering through structured questionnaire with technical/clinical staff of Vellore District - Vellore, Ambur, Ranipet, Walaja etc. Once the data collection is completed, the data was coded, cleaned, labelled and verified with regard to the missing values. The corrected data was taken for analysis. In this research, SPSS was utilized to test the reliability and validity of the instrument and to examine the perception of hospital employees whereas to examine the effects of performance expectancy, effort expectancy, and social influence constructs influence on behavioural intention measured is using Regression in AMOS 20. The usage behaviour determinants of behavioural intention and facilitating condition effect also measured using Regression in AMOS. The weights of items of the behavioural intention determinants and usage behaviour determinants were taken and regression formula was applied to constructs.

\section{Results and Analysis}

Table 1 shows the demographic profile of Clinical Staffs in the healthcare services. Out of five hundred and sixty-eight appropriate responses, 29.9 percent (170) were female clinical staffs and 70.1 percent are male clinical staffs (398), belongs to the age group of between 20-25 years (100 percent).

The experience/service in the medical field reported is 97.9 percent (556) with 0 -5 years, 2.1 percent (12) with $11-15$ years respectively.

Fig. 1 Testing Model to determine the direct effect of clinical staff's perceptions on performance expectancy, effort expectancy and social influence upon their behavioural intention as well as the effect of behavioural intention and facilitating conditions on usage behaviour.

Table 1. Socio-demographic profile of the participant

\begin{tabular}{|c|c|c|c|}
\hline \multicolumn{2}{|c}{$\begin{array}{c}\text { Demographic Details of } \\
\text { Clinical Staff's }\end{array}$} & \multicolumn{2}{c|}{$\begin{array}{c}\text { Number of } \\
\text { Participants (568) }\end{array}$} \\
\cline { 3 - 4 } \multicolumn{1}{|c|}{} & Frequency & Percent \\
\hline \multirow{4}{*}{ Gender } & Male & 398 & 70.1 \\
\cline { 2 - 4 } & Female & 170 & 29.9 \\
\hline \multirow{6}{*}{ Age } & $20-25$ & 568 & 100 \\
\cline { 2 - 4 } & $26-30$ & - & - \\
\cline { 2 - 4 } & $31-35$ & - & - \\
\cline { 2 - 4 } & $36-40$ & - & - \\
\cline { 2 - 4 } & $41-45$ & - & - \\
\cline { 2 - 4 } & $46-50$ & - & - \\
\cline { 2 - 4 } & Above 50 & - & - \\
\hline Experience & $0-5$ & 556 & 97.9 \\
\cline { 2 - 4 } & $6-10$ & - & - \\
\cline { 2 - 4 } & $11-15$ & 12 & 2.1 \\
\cline { 2 - 4 } & $16-20$ & - & - \\
\cline { 2 - 4 } & $21-25$ & - & - \\
\cline { 2 - 4 } & $26-30$ & - & - \\
\cline { 2 - 4 } & Above 31 & - & \\
\hline
\end{tabular}

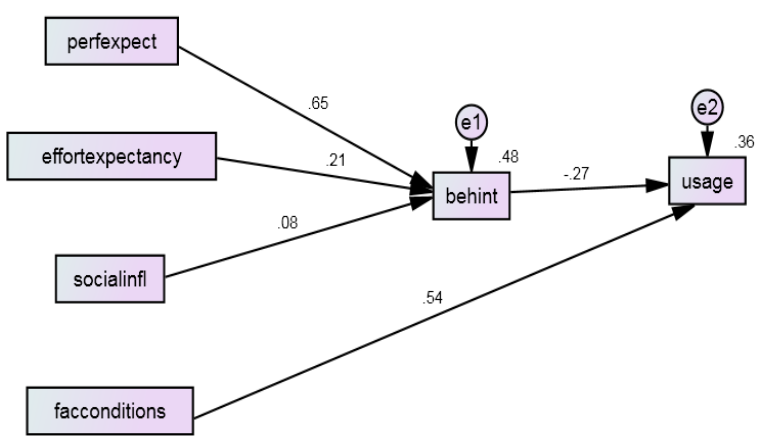

Figure 1: Testing Model

\section{Source: Primary Data}

Note: perfexpect $=$ Performance Expectancy, effortexpectancy = Effort Expectancy, socialinfl = Social Influence, behint = Behavioural Intention, facconditions $=$ Facilitating Conditions and usage $=$ Usage Behaviour or Likely to Use. 
An Analysis of the Impact of UTAUT Predictors on the Intention and usage of Electronic Health Records and Telemedicine from the Perspective of Clinical Staffs

Table 2. Regression Weights: (Clinical Staff - Default model)

\begin{tabular}{|l|c|c|c|c|}
\hline Regression Weights & Estimate & S.E. & C.R. & P \\
\hline $\begin{array}{l}\text { Behavioural Intention } \\
\text { <--- Performance } \\
\text { Expectancy }\end{array}$ & 1.021 & .047 & 21.516 & $* * *$ \\
\hline $\begin{array}{l}\text { Behavioural Intention } \\
\text { <--- Effort Expectancy }\end{array}$ & .379 & .054 & 7.073 & $* * *$ \\
\hline $\begin{array}{l}\text { Behavioural Intention } \\
\text { <--- Social Influence }\end{array}$ & .111 & .041 & 2.736 & $* * *$ \\
\hline $\begin{array}{l}\text { Usage <--- Facilitating } \\
\text { Conditions }\end{array}$ & 1.140 & .071 & 16.045 & $* * *$ \\
\hline $\begin{array}{l}\text { Usage Behaviour <--- } \\
\text { Behavioural Intention }\end{array}$ & -.414 & .052 & -8.033 & $* * *$ \\
\hline
\end{tabular}

Table 3. Standardized Regression Weights: (Clinical Staff - Default model)

\begin{tabular}{|l|c|}
\hline Standardized Regression Weights & Estimate (Beta Sig.) \\
\hline $\begin{array}{l}\text { Behavioural Intention <--- } \\
\text { Performance Expectancy }\end{array}$ & .652 \\
\hline $\begin{array}{l}\text { Behavioural Intention <--- Effort } \\
\text { Expectancy }\end{array}$ & .214 \\
\hline $\begin{array}{l}\text { Behavioural Intention <--- Social } \\
\text { Influence }\end{array}$ & .083 \\
\hline Usage <--- Facilitating Conditions & .538 \\
\hline $\begin{array}{l}\text { Usage Behaviour <--- Behavioural } \\
\text { Intention }\end{array}$ & -.269 \\
\hline
\end{tabular}

Table 4. Variances: (Clinical Staff - Default model)

\begin{tabular}{|l|c|c|c|c|}
\hline Variances & Estimate & S.E. & C.R. & P \\
\hline $\begin{array}{l}\text { Behavioural Intention <- } \\
-- \text { Performance } \\
\text { Expectancy }\end{array}$ & .193 & .011 & 16.837 & $* * *$ \\
\hline $\begin{array}{l}\text { Behavioural Intention <- } \\
-- \text { Effort Expectancy }\end{array}$ & .151 & .009 & 16.837 & $* * *$ \\
\hline $\begin{array}{l}\text { Behavioural Intention <- } \\
-- \text { Social Influence }\end{array}$ & .263 & .016 & 16.837 & $* * *$ \\
\hline $\begin{array}{l}\text { Usage <--- Facilitating } \\
\text { Conditions }\end{array}$ & .248 & .015 & 16.837 & $* * *$ \\
\hline e1 & .246 & .015 & 16.837 & $* * *$ \\
\hline e2 & .711 & .042 & 16.837 & $* * *$ \\
\hline
\end{tabular}

Table 5. Squared Multiple Correlations: (Clinical Staff - Default model)

\begin{tabular}{|l|c|}
\hline Dependent Variables & $\begin{array}{l}\text { Estimate (Combined } \\
\text { Variance }\end{array}$ \\
\hline Behavioural Intention & 0.479 \\
\hline Usage Behaviour & 0.362 \\
\hline
\end{tabular}

\section{Interpretation}

$[$ Behavioural Intention $=(0.65 *$ Performance Expectancy $)+\left(0.21^{*}\right.$ Effort Expectancy $)+$ (0.08*Social Influence)]

Table 2, 3, 4 and 5 shows the regression and correlation analysis for the clinical staff which has been used for further analysis. The above formula shows that one unit change in Performance Expectancy will result in 0.65 unit change in Behavioural Intention, one unit change in Effort
Expectancy will result in 0.21 unit change in Behavioural Intention and one unit change in Social Influence will result in 0.08 unit change in Behavioural Intention. It was found that all the three factors have a positive effect on Behavioural Intention to accept and use electronic health records and telemedicine. The R-Square value for Behavioural Intention is 0.48 ; it shows that 48 percent of variance or performance in Behavioural Intention is together explained by these three Factors. It clearly shows that by bringing positive perception on the three factors can alone cause 48 percent Behavioural Intention to use electronic health records and telemedicine and among the three factors Performance Expectancy seems to be more important. Hence the hypothesis H01 is accepted.

[Usage Behaviour $=\left(0.54^{*}\right.$ Facilitating Conditions $)$ $+(-0.27 *$ Behavioural Intention $)]$

The above formula shows that one unit change in Facilitating Conditions will result in 0.54 unit change in Usage Behaviour and one unit change in Behavioural Intention will result in - 0.27 unit change in Usage Behaviour. It was found facilitating conditions have a positive effect and behavioural intention have a negative effect on causing Usage Behaviour or likely to use behaviour. The R-Square value for Usage Behaviour is 0.36 ; it shows that 36 percent of variance or performance in Usage Behaviour is together explained by these three Factors. It clearly shows that by bringing positive perception on these two factors facilitating conditions can alone cause 54 percent of Usage Behaviour on electronic health records and telemedicine and among the two factors facilitating conditions seems to be more important. Hence the hypothesis of $\mathrm{HO2}$ is accepted. All the variables are statistically significant at $5 \%$ level $(p<0.05)$ and it is shown in Table 6. From the standardized regression weights table the results of hypotheses are given below:

Table 6. Anova for Significance

\begin{tabular}{|l|c|c|c|c|}
\hline $\begin{array}{l}\text { Determinants of } \\
\text { Usage Behaviour }\end{array}$ & $\begin{array}{c}\text { Beta } \\
\text { (Sig.) }\end{array}$ & $\begin{array}{c}\text { T - } \\
\text { Values }\end{array}$ & $\mathrm{P}$ & Results \\
\hline $\begin{array}{l}\text { Behavioural } \\
\text { Intention <--- } \\
\text { Performance } \\
\text { Expectancy }\end{array}$ & .652 & 16.837 & $* * *$ & Accepted \\
\hline $\begin{array}{l}\text { Behavioural } \\
\text { Intention <--- Effort } \\
\text { Expectancy }\end{array}$ & .214 & 16.837 & $* * *$ & Accepted \\
\hline $\begin{array}{l}\text { Behavioural } \\
\text { Intention <--- Social } \\
\text { Influence }\end{array}$ & .083 & 16.837 & $* * *$ & Accepted \\
\hline $\begin{array}{l}\text { Usage <--- } \\
\text { Facilitating } \\
\text { Conditions }\end{array}$ & .538 & 16.837 & $* * *$ & Accepted \\
\hline $\begin{array}{l}\text { Usage Behavioural } \\
<--- \text { Behavioural } \\
\text { Intention }\end{array}$ & -.269 & 16.837 & $* * *$ & Accepted \\
\hline
\end{tabular}

Note: ${ }^{* * *}$ Less than 0.01 Significance Level and ${ }^{* *}$ Less than 0.05 Significance Level 
As per clinical staff; one unit change in Performance Expectancy will result in 0.75 unit change in Behavioural Intention [11] , one unit change in Effort Expectancy will result in 0.21 unit change in Behavioural Intention and one unit change in Social Influence will result in 0.08 unit change in Behavioural Intention. It was found that all the three factors have a positive effect on Behavioural Intention to accept and use electronic health records and telemedicine. The R-Square value for Behavioural Intention is 0.48 ; it shows that 48 percent of variance or performance in Behavioural Intention is together explained by these three Factors. It clearly shows that by bringing positive perception on the three factors can alone cause 65 percent of Behavioural Intention to use electronic health records and telemedicine and among the three factors Performance Expectancy seems to be more important.

Also as per the clinical staff; one unit change in Facilitating Conditions will result in 0.54 unit change in Usage Behaviour and one unit change in Behavioural Intention will result in -0.27 unit change in Usage Behaviour. It was found facilitating conditions have a positive effect and behavioural intention have a negative effect on causing Usage Behaviour or likely to use behaviour. The R-Square value for Usage Behaviour is 0.36 ; it shows that 36 percent of variance or performance in Usage Behaviour is together explained by these three Factors. It clearly shows that by bringing positive perception on these two factors facilitating conditions can alone cause 54 percent of Usage Behaviour on electronic health records and telemedicine and among the two factors facilitating conditions seems to be more important. Hence the hypothesis $\mathrm{H} 01$ is accepted.

\section{Conclusions}

The principal purpose of the study is to validate the dimensions that portray the behavioural intention and use behaviour or likely to use in the context of electronic health records and telemedicine technologies. Technology adoption can significantly put in hospitals to improve good healthcare service. It is very important to understand and identify the requirements and perceptions of hospital employees for the implementation of technology.

The patients need not wait more for a lean period through technology adoption, electronic health records will help the doctors by providing the entire health information of the patient and telemedicine will helps the patients in avoiding number of visits and offering healthcare service in remote places through telemonitoring.
The technology adoption and technology acceptance and use from the perspective of information technology measured different dimensions both qualitatively and quantitatively. Further the authors have also suggested for further measurement of technology acceptance and use from other contexts.

\section{Managerial Implications}

It is observed that unless and until the management brings the positive perception in the minds of hospital employees and collaboration in the employees it is very difficult to implement the electronic health records and telemedicine. By introducing the electronic health records and telemedicine in a country like India; health care services can be made available even to rural and remote areas, increases quality of job, reduces the frequency of hospital visits, reduces cost, saves time, tele monitoring, proper documentation of health information, security of information will be improved. The governments and hospitals can identify the required hospital resources for implementing the electronic health records and telemedicine by considering the outcome and reducing time.

\section{Limitations and future research}

The study was carried out on both private and public sector hospitals and the future study can be on sector-specific as well as the electronic health records and telemedicine of e-health technologies were only studied and there are other e-health technologies to be tested. The perceptions of hospital employees towards acceptance and use of electronic health records and telemedicine was studied; the perceptions of pharmacists, medical representatives, and patients' perspective can also be carried. The relationships in UTAUT model was confirmed but the mediating and moderating variables can also identify and can test its validity from the Indian context.

\section{Acknowledgements}

This work is supported by FEDER Funds through the "Programa Operacional Factores de Competitividade - COMPETE" program and by National Funds through FCT "Fundação para a Ciência e a Tecnologia" under the project: FCOMP-01-0124-FEDER-PEstOE/EEI/UI0760/2011, PEst-OE/EEI/UI0760/2014, and PEst2015-2020.

\section{References}

[1] AlDossary, S., Martin-Khan, M. G., Bradford, N. K., \& Smith, A. C. (2017). A systematic review of the methodologies used to evaluate telemedicine service initiatives in hospital facilities. International journal of medical informatics, 97, 171-194. 
[2] Bickmore, T., Vardoulakis, L., Jack, B., \& PaascheOrlow, M. (2013, January). Automated promotion of technology acceptance by clinicians using relational agents. In Intelligent Virtual Agents (pp. 68-78). Springer Berlin Heidelberg.

[3] Chiang, M. F., Boland, M. V., Margolis, J. W., Lum, F., Abramoff, M. D., Hildebrand, P. L., \& American Academy of Ophthalmology Medical Information Technology Committee. (2008). Adoption and perceptions of electronic health record systems by ophthalmologists: an American Academy of Ophthalmology survey. Ophthalmology, 115(9), 1591-1597.

[4] Dixon, M. J., Marres, H. A., Edwards, S. J., Dixon, J., \& Cremers, C. W. (1994). Treacher Collins syndrome: correlation between clinical and genetic linkage studies. Clinical dysmorphology, 3(2), 96-103.

[5] Gheorghe. M. \&Petre, R. (2014). Integrating Data Mining Techniques into Telemedicine Systems. InformaticaEconomica, 18(1), 120-130.

[6] Jeyakodi, T., \& Herath, D. (2016). Acceptance and Use of Electronic Medical Records in Sri Lanka. Scientific Research Journal (SCIRJ), 4.

[7] Katzenstein, J., Yrle, A. C., Chrispin, B., Hartman, S., \& Lundberg, O. (2012). Telemedicine: An Innovative Technique in Healthcare Delivery. Academy of Health Care Management Journal, 8(1/2), 49.
[8] Narattharaksa, K., Speece, M., Newton, C., \& Bulyalert, D. (2016). Key success factors behind electronic medical record adoption in Thailand. Journal of health organization and management, 30(6), 985-1008.

[9] Tavares, J., \& Oliveira, T. (2017). Electronic Health Record Portal Adoption: a cross country analysis. BMC medical informatics and decision making, 17(1), 97.

[10] Ward, R., Stevens, C., Brentnall, P., \&Briddon, J. (2008). The attitudes of health care staff to information technology: a comprehensive review of the research literature. Health Information \& Libraries Journal, 25(2), 81-97.

[11] Zaidi, S. T. R., Marriott, J. L., \& Nation, R. L. (2008). The role of perceptions of clinicians in their adoption of a web-based antibiotic approval system: do perceptions translate into actions?. International journal of medical informatics, 77(1), 33-40.

[12] Zurovac, J., Dale, S., \& Kovac, M. (2012). Perceptions of Electronic Health Records and their effect on the quality of care: Results from a survey of patients in four states. Mathematica Policy Research.

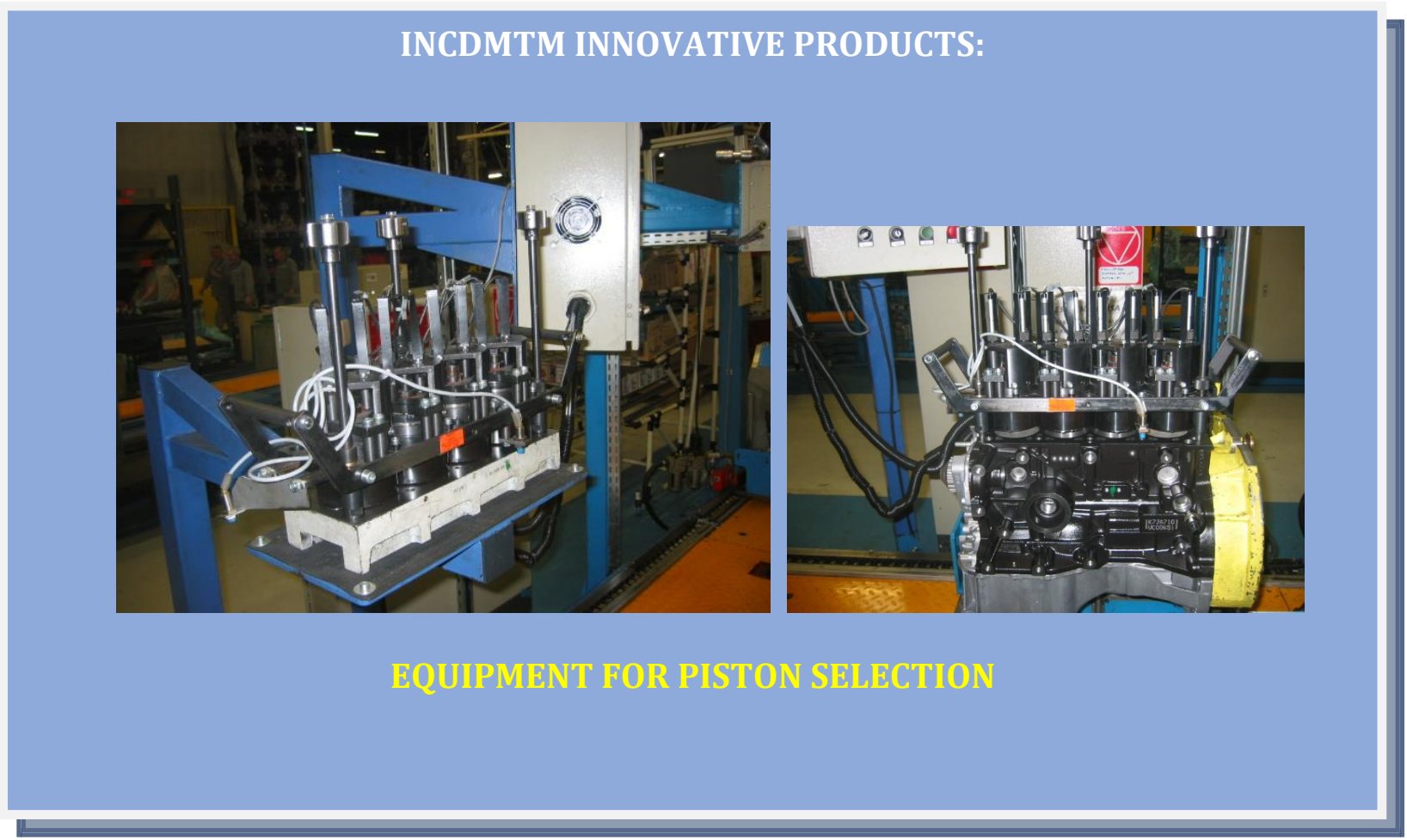

